\title{
Prototypic Features of Loneliness in a Stratified Sample of Adolescents
}

\author{
Mathias Lasgaard' \\ Ask Elklit \\ Department of Psychology, University of Aarhus, Denmark
}

\begin{abstract}
Dominant theoretical approaches in loneliness research emphasize the value of personality characteristics in explaining loneliness. The present study examines whether dysfunctional social strategies and attributions in lonely adolescents can be explained by personality characteristics. A questionnaire survey was conducted with 379 Danish Grade 8 students $(M=14.1$ years, $S D=0.4)$ from 22 geographically stratified and randomly selected schools. Hierarchical linear regression analysis showed that network orientation, success expectation and avoidance in affiliative situations predicted loneliness independent of personality characteristics, demographics and social desirability. The study indicates that dysfunctional strategies and attributions in affiliative situations are directly related to loneliness in adolescence. These strategies and attributions may preclude lonely adolescents from guidance and intervention. Thus, professionals need to be knowledgeable about prototypic features of loneliness in addition to employing a pro-active approach when assisting adolescents who display prototypic features.
\end{abstract}

Keywords: Loneliness, adolescence, personality, social strategies

The identification of prototypic features of lonely people is of large importance to loneliness research (Heinrich \& Gullone, 2006) and has the potential to guide optimal clinical intervention and planning of public prevention. The current study investigated, to what extent maladaptive strategies and attributions in affiliative situations are specific predictors of loneliness in adolescence, independent of personality characteristics.

\section{Loneliness in adolescence}

Available evidence suggests that loneliness increases during adolescence (Mahon, Yarcheski, Yarcheski, Cannella, \& Hanks, 2006) and is most prevalent during the adolescent years (Heinrich $\&$ Gullone, 2006). Loneliness in adolescence may to some extent be considered normative, because of the significant changes in social expectations and needs that adolescents undergo (Sippola \&

\footnotetext{
${ }^{1}$ Correspondence concerning this article should be addressed to Mathias Lasgaard at Aarhus University, Jens Chr. Skous Vej 4, 8000 Aarhus C, Denmark; +45 8942 4967; e-mail: mathiasl@psy.au.dk.
} 
Bukowski, 1999). However, it is important to distinguish between loneliness as a fundamental reality in human existence (Moustakas, 1961) and loneliness as a psychological reaction towards social deficiencies (Peplau \& Perlman, 1982). On the one hand, existential feelings of loneliness may be a natural part of adolescent life and to some extent considered positive as a source of personal development. On the other hand, some adolescents are captured in a state of deep loneliness with serious consequences for well-being and mental health. To consider the latter normative and constructive would be wrong. In fact, many studies have associated adolescent loneliness with mental health problems, in particular depressive affect (Mahon et al., 2006).

Loneliness has been defined in different ways, but most scholars agree that loneliness is an unpleasant and distressing, subjective experience that results from deficient social relationships (Peplau \& Perlman, 1982). The notion that loneliness is a subjective experience, and as such differs from solitude, is particularly important with regard to adolescents, who tend to be surrounded by peers, most commonly classmates. Thus, experiencing loneliness in adolescence often means feeling lonely in the crowd. In line with this observation, studies have shown that it is possible to feel lonely yet have many contacts. For instance, loneliness in undergraduate students does not predict differences in time spent alone and in daily activities (Hawkley, Burleson, Berntson, \& Cacioppo, 2003) likewise such is not highly related to the objective characteristics of the social milieu (Jones, 1981).

Loneliness, personality, and dysfunctional strategies and attributions

One important consideration when describing loneliness is that of individual differences. Dominant theoretical approaches within the field all emphasize the value of personality characteristics in explaining the unpleasant experience of loneliness and the associated deficiencies in lonely persons' social relationships. Drawing on psychodynamic theory, the social needs approach (Fromm-Reichmann, 1959; Sullivan, 1953) argues that loneliness arises from an inability to establish fulfilling social relationships due to personality traits and intrapsychic conflicts. The aforementioned are assumed to be formed by early childhood experiences with parents who failed to satisfy the child's basic needs of human intimacy. The interactionist approach argues that loneliness arises from the interplay between personality factors (e.g., 
extraversion), cultural factors and situational factors (Weiss, 1973; Weiss, 1982). Both the social needs approach and the interactionist approach is related to Bowlby's $(1969,1973)$ attachment theory, which has inspired studies that have associated loneliness in adolescence and adulthood with disrupted or insecure attachment styles (DiTommaso, Brannen-McNulty, Ross, \& Burgess, 2003; Hecht \& Baum, 1984). Finally, the cognitive approach views loneliness as the result of a discrepancy between the interpersonal relationships, which one perceives they have, and the interpersonal relationships which one wishes to have (e.g., Peplau, Miceli, \& Morasch, 1982). This approach additionally highlights low self-esteem and an internal, stable attributional style as predictors of loneliness.

The importance of personality characteristics in loneliness gains support from a wealth of studies. In line with other researchers (Asendorpf \& van Aken, 2003), this study distinguished between stable core personality characteristics and less stable surface personality characteristics. Research, primarily conducted with North American college students, has repeatedly related two main core personality characteristics to loneliness: extraversion and neuroticism (AmichaiHamburger \& Ben-Artzi, 2003). Studies with adolescent samples that have investigated loneliness and the two personality components typically find effect sizes in the range of .09 to .25 (Asendorpf \& van Aken, 2003; Neto \& Barros, 2000; Wilson, Sibanda, Sibanda, \& Wilson, 1989). Moreover, loneliness has been associated with general surface characteristics that are more susceptible to environmental influence, in particular low self-esteem. A meta-analysis of 30 adolescent samples (Mahon et al., 2006) indicated that the relationship between self-esteem and loneliness were in the range of a high medium effect size ( $r^{2}=.23$ to .25 ; outliers removed) within this age group.

Studies that compare the different impact of these personality characteristics on loneliness are rare and inconclusive. In an undergraduate study using multiple regression analysis both extraversion and neuroticism contributed significantly to loneliness, but the independent contribution of neuroticism was largerthan that of extraversion $\left(r^{2}=.18\right.$. vs. $r^{2}=.06$; Stokes, 1985). In contrast, extraversion and self-confidence (rather than neuroticism) predicted social loneliness 
in an adolescent study (Cheng \& Furnham, 2002). Accordingly, it is relevant to conduct further studies that compare the specific impact of different personality characteristics.

One important question that has been largely overlooked in previous research is to what extent the personality characteristics of lonely adolescents can explain associations with other related affective, cognitive, and behavioural features. One example is the common use of dysfunctional strategies and attributions in affiliative situations by lonely people. For instance, social avoidance, low network orientation, an internal, stable attributional style, and low success expectations and pessimism in affiliative situations, have been associated with loneliness (e.g., Johnson, LaVoie, Spenceri, \& Mahoney-Wernli, 2001; Laine, 1998; Nurmi, Toivonen, Salmela-Aro, \& Eronen, 1996; Van Buskirk \& Duke, 1991; Vaux, 1988). To our knowledge, it has not been investigated whether such social strategies and attributions essentially reflect personality characteristics or, opposed to this, are independent prototypic features of loneliness in adolescence.

In a recent study (Cacioppo et al., 2006), negative mood, anxiety, anger, optimism, selfesteem, and social support were all associated with loneliness independent of the Big Five personality traits (including extraversion and neuroticism) in undergraduate students. However, in the same study, avoidant thinking, positive affect, fear of negative evaluation, and social skills, failed to be associated with loneliness when the personality variables served as covariates, indicating that the extent to which loneliness is functionally independent of personality may vary in relation to different affective, cognitive, and behavioural features.

\section{Prototypic features of loneliness and gender}

Studies have shown that males and females have different social needs and friendship structures (Inderbitzen-Pisaruk, Clark, \& Solano, 1992). For instance, adolescent girls have more intimate friendships than boys. These findings suggest that there may be gender differences in the variables that are associated with adolescent loneliness. However, studies investigating gender differences in the prototypic features of lonely adolescents are not very common. InderbitzenPisaruk et al. (1992) found that self-esteem, social skills, and non-interpersonal controllability 
predicted loneliness in boys, whereas social anxiety, social skills, and interpersonal stability predicted loneliness in girls. Also, research has reported that male college students report a greater association between loneliness and negative self-perceived likeability than that reported by females (Schultz \& Moore, 1986). Moreover, some studies suggest that there is a greater association between loneliness and distress (e.g., mild depression and psychosomatic complaints) among male than female adolescents (see Koenig \& Abrams, 1999). However, studies that have investigated gender differences in the relationships between loneliness and extraversion and neuroticism have revealed inconclusive results (Saklofske, Yackulic, \& Kelly, 1986; Saklofske \& Yackulic, 1989).

The present study

Most studies of loneliness in adolescence have been based on convenience samples. In a recent meta-analytic study, 103 of 107 were samples of convenience (Mahon et al., 2006). Consequently, it is most likely that some parts of adolescent populations have been excluded or underrepresented in many existing studies, which to some extent limits generalization of the results. For instance, it is possible that the community studies have failed to include adolescents from rural areas attributable to their extended locality in relation to the research departments. Thus, stratified or population-based studies are needed. The present study investigated prototypic features of loneliness in a geographically stratified sample of Danish Grade 8 students.

Very few studies have investigated loneliness in samples from Denmark, a small country of approximately $5^{1 / 2}$ million citizens situated in the Scandinavian region of northern Europe. The country is highly secularised, has many dual-working families, a high divorce rate, and an extensive welfare system. Naturally, differences in interpersonal relationships and norms in various cultures may affect the degree and experience of loneliness. However, the patterns of factors (e.g., personality factors) that correlate with loneliness have been found to be similar across samples from diverse cultures (Anderson, 1999; Jones, Carpenter, \& Quintana, 1985; Neto \& Barros, 2003). Also, it has been indicated that there may be larger intracultural than cross-cultural differences in loneliness (DiTommaso, Brannen, \& Burgess, 2005). Therefore, we expected that 
prototypical features of lonely adolescents in Denmark would be similar to what have been observed in other countries.

As described, dominant theoretical approaches in loneliness research emphasize the value of personality characteristics in explaining loneliness. However, no previous studies have investigated whether the use of dysfunctional strategies and attributions in affiliative situations essentially reflect personality characteristics such as extraversion, neuroticism, and self-esteem, or, opposed to this, is a specific prototypic feature of loneliness. Assuming that personality characteristics are more general and stable variables than dysfunctional strategies and attributions in affiliative situations, the identification of a specific relationship between dysfunctional social strategies and attributions and loneliness in adolescence, could point towards prototypic features of loneliness that are domain specific and susceptible to clinical intervention.

In the present exploratory study, we aimed to assess the predictive validity of three such strategies and attributions (avoidance, success expectation, and network orientation) in explaining adolescent loneliness independent of three personality characteristics (extraversion, neuroticism, and self-esteem), social desirability and demographics. Given that studies investigating gender differences in the prototypic features of lonely adolescents are not very common, an additional purpose of the study was to investigate gender differences in the associations between loneliness and the investigated personality characteristics, strategies, and attributions. The personality characteristics included in the study were chosen because they consistently have been associated with loneliness, whereas the strategies and attributions in affiliative situations were chosen because they previously have been associated with loneliness. Given that loneliness is a very unpleasant feeling, it also seemed wise to control for social desirability that could influence the responses of participating adolescents.

\section{Methods}

\section{Participants and Procedure}

The data employed in this study was collected from a questionnaire survey with a stratified sample of 379 Grade 8 students. Grade 8 students were chosen as participants because of the fact 
that the majority of the Danish adolescents of this year group partake in education in a public or private school (97\% in 2005; Statistics Denmark, 2007a). Thus, it was possible to include a geographically representative sample of the target population in the study. Attributable to the narrow focus on Grade 8 students, the majority of the participants were 14 years old $(M=14.1 ; S D$ $=0.4$; range $=13-17)$. Fifty-three percent were boys. The demographic characteristics of the sample can be seen in Table 1 .

Table 1

Sample Characteristics $(N=379)$ versus National Characteristics from Statistics Denmark

\begin{tabular}{llll} 
Variables & Sample & National \\
Characteristics & \multicolumn{2}{c}{ Characteristics } \\
& (Mean & or & (Mean or \\
& Percentage) & Percentage)
\end{tabular}

\begin{tabular}{lll}
\hline Demographics & 14.1 & $14.1^{a}$ \\
Age & 53 & $51^{a}$ \\
Gender, boys & 94 & $95^{a}$ \\
Country of birth, Denmark & & \\
Living conditions & 71 & $64^{b}$ \\
Two-parent family & 28 & 34 \\
Single-parent family & 1 & 2 \\
Other & & \\
Siblings & 6 & $5^{b}$ \\
Only child & 41 & 37 \\
One sibling & 53 & 58 \\
Two or more siblings & 89 & $85^{a}$ \\
Type of education, public school & & \\
Residential location & 26 & \\
Rural area & 24 & \\
Village or small city $(\cdot 10,000$ inhabitants) & 50 & \\
Large city (> 10,000 inhabitants) &
\end{tabular}

Note. The mixed category "living with other" was excluded from the analysis. "National characteristics of Danish Grade 8 students (Statistics Denmark, 2007a; based on 2005-figures). ' National 
characteristics of 14-year-old persons in Denmark (Statistics Denmark, 2007b; based on 2005figures). 
The procedure followed that of a previous national study with Danish Grade 8 students (Elklit, 2002). The sample was geographically stratified, using the number of Grade 8 students in counties (Statistics Denmark, 2007a; based on 2005-figures) to define 10 different geographical areas of approximately equal size. From these 10 areas 39 randomly selected schools that taught Grade 8 students were approached. At the outset 30 schools (three from each area) were approached. However, three schools immediately declined to participate due to time constraints. Therefore, three additional randomly selected schools from the same areas as the declining schools were approached. Moreover, only one school from the capital area responded to the survey. Therefore, six additional randomly selected schools from this area were approached, with the aim of obtaining a more geographically representative distribution of the participants.

The study was introduced to the headmaster of the selected schools with the purpose of recruiting one randomly selected class from each school. If the selected school taught more than one Grade 8 class, headmasters were informed that as only one class would be needed from each school, one would be randomly selected for inclusion (the primacy of the initials of the class teacher decided the class). The class teacher received a letter describing the aim of the study, the procedure of the data collection, and confidentiality procedures. Therefore it was the onus of the class teacher to monitor all data collection. Due to the sensitive nature of the questionnaire, the importance of both confidentiality and support from the teacher was stressed.

Twenty-two of the 39 schools that were approached agreed to participate. Each class consisted of between 6 to 24 students $(M=17.2$ students, $S D=4.0)$, on average $90 \%$ of the students were present on the day of the study. All students present participated in the study. The geographical spread of the participants was deemed satisfactory. Also, the sample characteristics were quite similar to national characteristics of Grade 8 students or 14-year-old persons in Denmark (see Table 1). 
Measures

The first part of the questionnaire contained demographic questions about gender, age, birthplace, living conditions (living with both parents, single parent or others), number of siblings, and residential location (rural areas, villages or small cities [ 10,000 inhabitants], and large cities $[10,000-1,500,000$ inhabitants]).

Loneliness was assessed using the third version of UCLA (UCLA-3; Russell, 1996), which is the most frequently used standardized self-report scale for measuring loneliness in adolescent and adult populations (Hartshorne, 1993). The scale consists of 20 items (11 positive and 9 negative) and measures general feelings of loneliness, social isolation, and satisfaction or dissatisfaction with one's social interactions. Items are rated on a 4-point Likert scale according to the rate of frequency, ranging from 1 (never) to 4 (always) with higher scores reflecting higher loneliness. The scale has satisfactory psychometric properties (Russell, 1996). Using data from the present study, a translated/back-translated Danish version of the UCLA-3 showed high internal consistency $(\alpha=$ .92; Lasgaard, 2007). Moreover, correlations between the UCLA and measures of loneliness, selfesteem, and depression, supported the convergent and discriminant validity of the scale (Lasgaard, 2007).

The questionnaire survey also included a number of other measures from which the following were selected: The subscales Extraversion and Neuroticism from the Eysenck Personality Questionnaire - Revised Short Scale (EPQ-RSS; Eysenck \& Eysenck, 1991) were included to measure two well-established core personality traits. The scale was translated/back-translated into Danish. Each subscale comprises 12 statements scored "yes" or "no", and a high score on a subscale indicates that the trait is dominant in the respondent. Both subscales showed good internal consistency in the study (Extraversion $\alpha=.83$; Neuroticism $\alpha=.84$ ).

The Rosenberg Self-Esteem Scale (SES; Rosenberg, 1965) was used to measure a general surface characteristic that has been associated with loneliness in many studies. The scale comprises 10 items, scored on a 4-point Likert scale; a high score on the scale reflects high self- 
esteem. The SES has been translated into Danish by A. Elklit and showed good internal consistency in the present study $(\alpha=.88)$.

Three strategies and attributions in affiliative situations were investigated in the study. The Strategy and Attribution Questionnaire (Nurmi, Salmela-Aro, \& Haavisto, 1995) measures a broad range of strategies and attributions. In the present study, two subscales were used to measure Success Expectation and Avoidance in the affiliative context. The subscales were translated/backtranslated into Danish. The Success Expectation subscale comprises four items, whereas the Avoidance subscale comprises six items. Both scales were scored on a 4-point Likert scale and a high score on the scales reflect high expectations of social success and high avoidance. The subscales showed satisfactory internal consistency in the present study (Success Expectation $\alpha=$ .74; Avoidance $\alpha=.77$ ). The Network Orientation Scale (NOS; Vaux, Burda, \& Stewart, 1986) was included to measure the willingness to make use of social support resources. The NOS comprises 20 items, scored on a 4-point Likert scale with higher score on the scale indicating poor network orientation. The scale was translated/back-translated into Danish. The NOS showed good internal consistency in the present study $(\alpha=.74)$.

A 13-item short version (MC Form C; Reynolds, 1982) of the Marlowe-Crowne Social Desirability Scale (Crowne \& Marlowe, 1960) was included to control for social desirability. The MC Form C, one of the best short versions in comparison with other abbreviated scales, correlates highly with the full-length instrument (Andrews \& Meyer, 2003; Reynolds, 1982). The MC Form C is scored on a 2-point scale (true or false) with a high score indicating high social desirability and was translated/back-translated into Danish. The scale showed a modest, but acceptable internal consistency in the present study $(\alpha=.64)$.

\section{Data analysis}

Hierarchical linear regression (HLR) was performed to evaluate to what extent the various independent measures predicted the score on the UCLA. HLR is a theoretically driven model for entering variables in the model rather than a statistically driven model such as a stepwise analysis. 
In step 1 in the regression equation, the demographic variables (gender, country of birth, living with both parents vs. single parent, number of siblings, and residential location) were entered. Also, to control for biased responding, social desirability was included. Then, in step 2 the measures of personality characteristics were entered, followed in step 3 by the measures of attributions and strategies in affiliative situations. The rationale was that the general and more stable variables (in particular, extraversion and neuroticism) were entered before the variables that were specifically related to the affiliative domain. Finally, the HRL analysis was performed separately for boys and girls. Following the guidelines of Aiken and West (1991) we explored whether the associations between loneliness, and personality characteristics, and attributions and strategies in affiliative situations were moderated by gender. This was done by testing the equality of the regression coefficients for boys and girls (Fife-Schaw, 2006).

By examining tolerance and the Variance Inflation Factor all reported HLR models were checked for multicollinearity between independent variables. The analyses did not indicate problems with multicollinearity. Prior to data analysis, the data were screened for errors. The percentage of missing values was small (0.3-7.1\%). The Expectation Maximization (EM) algorithm, which has been demonstrated to be an effective method of dealing with missing data (Bunting, Adamson, \& Mulhall, 2002), was performed to impute missing data on all included scales. The EM algorithm is an iterative optimization method used for finding maximum likelihood estimates of unknown parameters in latent variables, given measurement data. Maximum likelihood estimation is based on the premise that the observed measures provide indirect information about the unobserved measures and is a common method of imputation. The Little's MCAR test (Little, 1988) was non-significant, which indicates that data was missing at random. Imputation of missing data was performed using SPSS 16.00.

\section{Results}

The zero-order correlations of the variables in the study can bee seen in Table 2, whereas the results of the HLR analyses can be seen in Table 3. The first step of the HRA showed that the demographic factors and social desirability explained $4 \%$ of the variance. The only significant 
predictor variable was social desirability, associated with less loneliness. In step 2 the relationship between loneliness and the three personality variables were examined. Replicating prior research, neuroticism was associated with more loneliness, whereas extraversion and self-esteem were associated with less loneliness. The model explained $52 \%$ of the variance. Including the measures of attributions and strategies in affiliative situations in step 3, success expectation, avoidance and network orientation proved to be significant predictors of loneliness independent of the personality characteristics, demographics, and social desirability. Moreover, the three personality characteristics remained significant predictors of loneliness. The expanded model explained $61 \%$ of the variance in loneliness $\left(\cdot R^{2}=8 \%, p<.005\right)$. The semipartial correlations squared that indicate the effect size contribution of each variable independently of the other variables can be seen in Table 3.

Table 2

Means, SDs and Intercorrelations of the Variables in the Study

\begin{tabular}{|c|c|c|c|c|c|c|c|c|}
\hline Measure & 1 & 2 & 3 & 4 & 5 & 6 & 7 & 8 \\
\hline 1. Loneliness & - & $-.53 * * *$ & $.57 * * *$ & $-.55 * * *$ & $-.64 * * *$ & $.63 * * *$ & $.52 * * *$ & $-.15 * *$ \\
\hline 2. Extraversion & & - & $-.36 * * *$ & $.30 * * *$ & $.43 * * *$ & $-.61 * * *$ & $-.35 * * *$ & .03 \\
\hline 3. Neuroticism & & & - & $-.60 * * *$ & $-.47 * * *$ & $.46^{* * *}$ & $.32 * * *$ & $-.29 * * *$ \\
\hline 4. Self-esteem & & & & - & $.55 * * *$ & $-.46 * * *$ & $-.41 * * *$ & $.19 * * *$ \\
\hline 5. Success expectation & & & & & - & $-.64 * * *$ & $-.49 * * *$ & $.17^{* *}$ \\
\hline 6. Avoidance & & & & & & - & $.42 * * *$ & .01 \\
\hline 7. Low network orientation & & & & & & & - & $-.21 * * *$ \\
\hline 8. Social desirability & & & & & & & & - \\
\hline \multirow[t]{2}{*}{ Mean (SD) } & 37.63 & 20.69 & 16.11 & 31.50 & 13.13 & 11.65 & 43.79 & 19.92 \\
\hline & $(10.12)$ & $(3.00)$ & $(3.34)$ & $(5.40)$ & $(1.98)$ & $(3.22)$ & $(6.00)$ & $(2.71)$ \\
\hline
\end{tabular}


Table 3

Hierarchical Regression Analysis for Variables Predicting Loneliness $(N=379)$

\begin{tabular}{|c|c|c|c|c|c|c|}
\hline Variable & $B$ & $S E B$ & $\beta$ & $\mathrm{t}$ & $p$ & $r_{s p}^{2}$ \\
\hline \multicolumn{7}{|l|}{ Step 1} \\
\hline Gender & -0.25 & 1.05 & -.01 & -0.24 & .812 & .00 \\
\hline Country of birth, & -1.14 & 2.13 & -.03 & -0.54 & .592 & .00 \\
\hline \multicolumn{7}{|l|}{ Denmark } \\
\hline Two-parent family & -1.89 & 1.15 & -.09 & -1.64 & .103 & .01 \\
\hline Number of siblings & -0.03 & 0.87 & .00 & -0.04 & .971 & .00 \\
\hline Residential location & -0.84 & 0.63 & -.07 & -1.34 & .182 & .00 \\
\hline Social desirability & -0.58 & 0.19 & -.15 & 3.00 & $.003 * *$ & .02 \\
\hline \multicolumn{7}{|l|}{ Step 2} \\
\hline Gender & -2.46 & 0.78 & -.12 & -3.14 & $.002 * *$ & .01 \\
\hline Country of birth, & -1.63 & 1.52 & -.04 & -1.07 & .284 & .00 \\
\hline \multicolumn{7}{|l|}{ Denmark } \\
\hline Two-parent family & 0.12 & 0.83 & -.00 & 0.01 & .989 & .00 \\
\hline Number of siblings & -0.33 & 0.62 & -.02 & -0.53 & .594 & .00 \\
\hline Residential location & -0.19 & 0.45 & -.02 & -0.42 & .679 & .00 \\
\hline Social desirability & -0.04 & 0.15 & -.01 & -0.27 & .786 & .00 \\
\hline Extraversion & -1.07 & 0.14 & -.32 & -7.80 & $<.0005 * * *$ & .08 \\
\hline Neuroticism & 0.96 & 0.15 & .31 & 6.25 & $<.0005 * * *$ & .05 \\
\hline
\end{tabular}


Table 3 continued

\begin{tabular}{|c|c|c|c|c|c|c|}
\hline Variable & $B$ & $S E B$ & $\beta$ & $\mathrm{t}$ & $P$ & $r_{\mathrm{sp}}^{2}$ \\
\hline Self-esteem & -0.55 & 0.09 & -.30 & -6.40 & $<.0005^{* * *}$ & .05 \\
\hline \multicolumn{7}{|l|}{ Step 3} \\
\hline Gender & -0.89 & 0.74 & -.04 & -1.20 & .230 & .00 \\
\hline Country of birth, & -0.95 & 1.38 & -.02 & -0.69 & .492 & .00 \\
\hline \multicolumn{7}{|l|}{ Denmark } \\
\hline Two-parent family & 0.04 & 0.75 & .00 & 0.05 & .958 & .00 \\
\hline Number of siblings & -0.33 & 0.56 & -.02 & -0.58 & .562 & .00 \\
\hline Residential location & -0.10 & 0.41 & .01 & 0.23 & .819 & .00 \\
\hline Social desirability & 0.03 & 0.14 & .01 & 0.22 & .828 & .00 \\
\hline Extraversion & -0.52 & 0.15 & -.15 & -3.58 & $<.0005^{* * *}$ & .01 \\
\hline Neuroticism & 0.71 & 0.14 & .23 & 5.02 & $<.0005^{* * *}$ & .03 \\
\hline Self-esteem & -0.23 & 0.09 & -.12 & -2.63 & $.009 * *$ & .01 \\
\hline Success expectation & -1.08 & 0.25 & -.21 & -4.31 & $<.0005^{* * *}$ & -.02 \\
\hline Avoidance & 0.53 & 0.16 & .17 & 3.24 & $.001 * *$ & .01 \\
\hline Low network & 0.27 & 0.07 & .16 & 3.96 & $<.0005^{* * *}$ & .02 \\
\hline
\end{tabular}

Note. $R^{2}=.04$ for Step $1(p<.05) ; \cdot R^{2}=.48$ for Step $2(p<.0005) ; \cdot R^{2}=.09$ for Step $3(p<.0005)$.

$p<.05 .{ }^{* *} p<.005 .{ }^{* * *} p<.0005$.

The result of the full HRL analysis performed separately for boys and girls can bee seen Table 4 (for simplicity, proceeding steps are not shown). Extraversion, neuroticism, success expectation, social avoidance, and network orientation, were significant predictors of loneliness in both boys and girls. Self-esteem predicted loneliness in boys only. However, testing the equality of the regression coefficients for boys and girls, no significant gender differences emerged with regard to any of six the variables. Both models were highly significant and explained $58 \%$ of the variance in loneliness in boys, and $66 \%$ of the variance in loneliness in girls. 
Table 4

Hierarchical Regression Analysis for Variables Predicting Loneliness in Boys and Girls ${ }^{a}$

\begin{tabular}{|c|c|c|c|c|c|c|}
\hline Variable & $B$ & $S E B$ & $\beta$ & $\mathrm{t}$ & $p$ & $r_{s p}^{2}$ \\
\hline \multicolumn{7}{|l|}{ Boys $(n=199)$} \\
\hline \multicolumn{7}{|l|}{ Step 3} \\
\hline Country of birth, & -2.87 & 2.10 & -.07 & -1.37 & .173 & .00 \\
\hline \multicolumn{7}{|l|}{ Denmark } \\
\hline Two-parent family & -0.10 & 1.15 & .00 & -0.09 & .931 & .00 \\
\hline Number of siblings & -0.35 & 0.79 & -.02 & -0.44 & .658 & .00 \\
\hline Residential location & -0.05 & 0.61 & .00 & -0.08 & .934 & .00 \\
\hline Social desirability & -0.20 & 0.19 & -.05 & -1.04 & .302 & .00 \\
\hline Extraversion & -0.51 & 0.20 & -.16 & -2.52 & $.013 *$ & .01 \\
\hline Neuroticism & 0.67 & 0.21 & .20 & 3.14 & $.002 * *$ & .02 \\
\hline Self-esteem & -0.26 & 0.12 & -.13 & -2.11 & $.036^{*}$ & .01 \\
\hline Success expectation & -1.23 & 0.35 & -.25 & -3.54 & $.001 * *$ & .03 \\
\hline Avoidance & 0.45 & 0.22 & .15 & 2.05 & $.042 *$ & .01 \\
\hline Low network & 0.21 & 0.10 & .12 & 2.06 & $.041^{*}$ & .01 \\
\hline orientation & & & & & & \\
\hline
\end{tabular}

Girls $(n=180)$

Step 3

Country of birth,

0.57

1.87

.01

0.30

.762

.00

Denmark

(table continues) 
Table 4 continued

\begin{tabular}{|c|c|c|c|c|c|c|}
\hline Variable & $B$ & $S E B$ & $\beta$ & $\mathrm{t}$ & $P$ & $r_{s p}^{2}$ \\
\hline Two-parent family & 0.39 & 1.03 & .02 & 0.38 & .702 & .00 \\
\hline Number of siblings & -0.34 & 0.81 & -.02 & -0.41 & .680 & .00 \\
\hline Residential location & 0.39 & 0.57 & .03 & 0.68 & .501 & .00 \\
\hline Social desirability & 0.28 & 0.19 & .08 & 1.46 & .147 & .00 \\
\hline Extraversion & -0.60 & 0.22 & -.16 & -2.74 & $.007 *$ & .12 \\
\hline Neuroticism & 0.73 & 0.20 & .25 & 3.66 & $<.0005^{* * *}$ & .03 \\
\hline Self-esteem & -0.21 & 0.13 & -.11 & -1.62 & .107 & .00 \\
\hline Success expectation & -0.82 & 0.39 & -.15 & -2.09 & $.038 *$ & .01 \\
\hline Avoidance & 0.63 & 0.25 & .19 & 2.49 & $.014^{*}$ & .01 \\
\hline Low network & 0.35 & 0.10 & .21 & 3.70 & $<.0005^{* * *}$ & .03 \\
\hline
\end{tabular}

Note. ${ }^{a}$ For simplicity, only the full model (step 3 ) is shown.

$R^{2}=.04$ for Step 1 in boys; $\cdot R^{2}=.45$ for Step 2 in boys $(p<.0005) ; \cdot R^{2}=.08$ for Step 3 in boys $(p<.0005) . R^{2}=$

.03 for Step 1 in girls; $\cdot R^{2}=.53$ for Step 2 in girls $(p<.0005) ; \cdot R^{2}=.10$ for Step 3 in girls $(p<.0005)$.

${ }^{*} p<.05 .{ }^{* *} p<.005 . * * * p<.0005$.

\section{Discussion}

Theoretical analyses have stressed the importance of personality in loneliness, and consistent with the results of previous research, the present study established that loneliness was positively related to neuroticism and negatively related to extraversion and self-esteem (independent of demographics and social desirability). In fact, the three personality characteristics explained more than half of the variance in loneliness, signifying the relevance of investigating the relationship between loneliness and personality. The effect sizes of the three factors were similar $\left(r_{s p}^{2}=.05-.08\right.$, all $\left.p<.005\right)$. This finding differs from previous studies, where the independent contribution of the factors has differed substantially (Cheng \& Furnham, 2002; Stokes, 1985). 
However, none of the previous studies investigated exactly the same combination of factors, and only the present study controlled for demographic factors and social desirability.

More importantly, when including avoidance, success expectation, and network orientation in the model, avoidance and low network orientation were significantly associated with more loneliness, whereas success expectations were associated with less loneliness. Hence, the three personality characteristics did not explain the associations between adolescent loneliness and avoidance, success expectation, and network orientation. The finding indicates that dysfunctional strategies and attributions in affiliative situations are specific prototypic features of loneliness in adolescence and the inclusion of the three factors raised the explained variance with $9 \%$.

As mentioned, the study indicates that a low expectation of future social success is a specific predictor of loneliness. However, one could speculate that success expectation in affiliative situations partly reflects a cognitive dimension of general self-esteem that often is part of a package of beliefs and behaviours that interfere with initiating or maintaining satisfying social relationships (Peplau et al., 1982). Adolescents who feel useless and show little self-confidence are likely to take little social initiative and will often be perceived by other adolescents as an unattractive peer, further increasing the risk of social deprivation. Feelings of loneliness may also have a negative effect on self-esteem that is often based on perceptions of personal experiences and feedback from significant others (Meggert, 1989). Without friends adolescents may feel alone in the search for their identity, and repeated experiences of rejection or a general lack of interest from peers in this critical development period may confirm a negative self-image, decrease success expectations, and increase feelings of uselessness. In that sense, the relationship between loneliness and low success expectation as well as self-esteem is likely to be bi-directional (Peplau et al., 1982).

At first, it would appear that the relationship between loneliness and avoidance of social situations is a contradiction. Given that loneliness is a reaction towards social deficiencies, it may seem odd that lonely adolescents tend to avoid situations that could lead to the initiation of satisfying peer relationships. However, lonely adolescents probably shun social situations due to anxiety related to such. This does not, however, imply that these adolescents do not long to 
engage with a peer group. As such, the avoidance of social situations in lonely adolescents may be regarded as a symptom of social anxiety, linked with loneliness in previous research (Johnson et al., 2001).

Research has repeatedly related social support to loneliness (Mahon et al., 2006). However, the specific relationship between loneliness and a poor network orientation in the present study stresses the importance of individual differences in the willingness and ability to use social support resources. Although some lonely adolescents presumably do lack social support, others seem to find it inadvisable to draw on a network and therefore may not reach out for help when it is available. Future research may further investigate the relationship between loneliness, perceived social support, and the use of support resources.

As mentioned above, the three personality characteristics remained significant predictors of loneliness when including the strategies and attributions in affiliative situations in the model. However, the independent contribution of the three factors was reduced. Noteworthy, the effect of extraversion on loneliness was diminished by more than half. Extraversion is associated with a greater need for stimulation due to a lower level of cortical arousal, which might manifest itself in behaviours that increase the extent of social contacts, and thereby in turn reduce the likelihood of experiencing loneliness (Saklofske \& Yackulic, 1989). In undergraduate students, the relationship between extraversion and loneliness has been found to be mediated by social network variables, indicating that extraverts are less lonely because they have large networks (Stokes, 1985). In line with this finding, the investigated strategies and attributions (e.g., avoidance) could be likely to have a negative impact on the actual social network, which may explain why the inclusion of these factors reduced the effect of extraversion.

In contrast, neuroticism was the strongest predictor of loneliness in the expanded model, indicating that neuroticism is an important prototypic feature of loneliness in adolescence. The predictive value of neuroticism may be explained by the trait being associated with a sensitive and worrying approach to relational deficits and a limited capacity to enjoy satisfying relationships (Saklofske et al., 1986). In line with this suggestion, neuroticism has been shown to predict 
loneliness independent of social network variables in undergraduate students, indicating that loneliness and neuroticism are related at the cognitive rather than the behavioural level (Stokes, 1985).

Given that the relation between self-esteem and loneliness in adolescence has been reported to be in the range of a high-medium effect size (Mahon et al., 2006), it is also noteworthy that the inclusion of the strategy and attribution variables in the model diminished the effect of selfesteem by more than half. Possibly, the relationship between self-esteem and loneliness is mediated by the strategies and attributions that people apply in social situations, as indicated by a study of undergraduate students (Nurmi, Toivonen, Salmela-Aro, \& Eronen, 1997).

Previous studies have associated self-esteem and self-perceived likeability with loneliness in boys (Inderbitzen-Pisaruk et al., 1992; Schultz \& Moore, 1986). Similarly, the HRL analysis performed separately for boys and girls indicated that self-esteem predicted loneliness in boys only. However, the association between self-esteem and loneliness was not significantly moderated by gender. Likewise, no gender differences emerged with regard to the other five predictors of loneliness variables. This finding differs from previous studies that have pointed to the existence of different gender difference and may be explained by methodological differences between the studies in regard to the performed data analysis and the level of representativeness of the samples.

Additionally, loneliness was not predicted by any demographic variables in the full model, which is in line with previous studies that have found psychosocial factors to be more predictive of loneliness than demographic variables (Neto \& Barros, 2000; Uruk \& Demir, 2003). Finally, social desirability only seemed to have a limited influence on the responses of the participating adolescents as indicated by the small correlations between social desirability and the other investigated psychosocial variables $(r=.01-.29)$.

As expected, the pattern of associations between loneliness and personality characteristics, social strategies and attributions, and demographics were generally consistent with previous studies, indicating that the prototypical features of lonely adolescents in Denmark are not unique to the investigated Danish adolescent sample, but are in fact similar to what have been observed in other countries. 


\section{Implications for practice}

Earlier research has found that lonely people attribute their interpersonal failures and loneliness to personal and hardly changeable characteristics such as personality traits rather than situational or changeable characteristics such as strategies chosen (see Heinrich \& Gullone, 2006). However, the present study indicates that dysfunctional social strategies and attributions in affiliative situations are directly related to loneliness. This finding clearly indicates that school interventions and counselling may benefit from focusing on social strategies and attributions, for instance, by developing programs that may help lonely adolescents change their tendency to avoid social situations. So far, social skills training have proved to be an effective intervention against loneliness (Adams, Openshaw, Bennion, \& Mills, 1988; King, Specht, Schultz, \& Warr-Leeper, 1997).

The specific associations between adolescent loneliness and low network orientation and avoidance of social situations underlines the notion that lonely adolescents will often be resistant to seek help and acknowledge to others that they need assistance. Therefore, they may be likely to hide and be overlooked in the classroom and other social arenas, which preclude them from guidance and intervention. In consequence, clinicians, counsellors, teachers, and social workers need to be knowledgeable about the lonely prototype in addition to employing a pro-active approach when assisting adolescents who display prototypic features.

\section{Limitations}

The present study has some limitations and caution must be exercised when interpreting the findings. The sample comprised only 379 students from 10 areas, which does not allow precise estimates of the population parameters. Also, the comparison between sample characteristics and national characteristics is a very simple analysis, which is why caution must be exercised with regard to generalization of the findings. Nevertheless, we suppose that the geographical stratification and random selection of the invited schools and classes strengthen the 
generalisability of the results of the present study in comparison with studies based on convenience samples.

Also, the present study was exploratory rather than driven by theory. This is a clear limitation and future studies would benefit from testing a theoretical model of the relationship between personality characteristics and social strategies and attributions. Additionally, more personality factors (e.g., the Big Five personality traits) and more strategies and attributions in affiliative situations could have been included. Finally, the correlational nature of the study does not allow conclusions about causality.

Nonetheless, the study demonstrated that three personality characteristics (extraversion, neuroticism, and self-esteem), which have been repeatedly related to loneliness, did not explain the use of dysfunctional social strategies and attributions in lonely adolescents. This finding points to the potential of interventions targeting the social strategies and attributions of lonely adolescents.

\section{References}

Adams, G. R., Openshaw, D. K., Bennion, L., \& Mills, T. (1988). Loneliness in late adolescence: A social skills training study. Journal of Adolescent Research, 3, 81-96.

Aiken, L. S., \& West, S. G. (1991). Multiple Regression: Testing and interpreting interactions. Newbury Park, CA: Sage.

Amichai-Hamburger, Y., \& Ben-Artzi, E. (2003). Loneliness and Internet use. Computers in Human Behavior, 19, 71-80.

Anderson, C. A. (1999). Attributional style, depression, and loneliness: A cross-cultural comparison of American and Chinese students. Personality and Social Psychology Bulletin, 25, 482-499.

Andrews, P., \& Meyer, R. G. (2003). Marlowe-Crowne Social Desirability Scale and short form C: Forensic norms. Journal of Clinical Psychology, 59, 483-492.

Asendorpf, J. B., \& van Aken, M. A. G. (2003). Personality-relationship transaction in adolescence: Core versus surface personality characteristics. Journal of Personality, 71, 629-666.

Bowlby, J. (1969). Attachment and loss: Volume 1: Attachment. London: Hogarth Press. 
Bowlby, J. (1973). Attachment and loss: Volume 2: Separation, anxiety and anger. London: Hogarth Press. Bunting, B. P., Adamson, G., \& Mulhall, P. (2002). A Monte Carlo examination of an MTMM model with planned incomplete data structures. Structural Equation Modeling, 9, 369-389.

Cacioppo, J. T., Hawkley, L. C., Ernst, J. M., Burleson, M., Berntson, G. G., Nouriani, B., \& Spiegel, D. (2006). Loneliness within a nomological net: An evolutionary perspective. Journal of Research in Personality, 40, 1054-1085.

Cheng, H., \& Furnham, A. (2002). Personality, peer relations, and self-confidence as predictors of happiness and loneliness. Journal of Adolescence, 25, 327-339.

Crowne, D. P., \& Marlowe, D. (1960). A new scale of social desirability independent of psychopathology. Journal of Consulting Psychology, 24, 349-354.

DiTommaso, E., Brannen, C., \& Burgess, M. (2005). The universality of relationship characteristics: A cross-cultural comparison of different types of attachment and loneliness in Canadian and visiting Chinese students. Social Behavior and Personality, 33, 57-68.

DiTommaso, E., Brannen-McNulty, C., Ross, L., \& Burgess, M. (2003). Attachment styles, social skills and loneliness in young adults. Personality and Individual Differences, 35, 303-312.

Elklit, A. (2002). Victimization and PTSD in a Danish national youth probability sample. Journal of the American Academy of Child and Adolescent Psychiatry, 41, 174-181.

Eysenck, H. J., \& Eysenck, S. B. G. (1991). Manual of the Eysenck Personality Scales. London: Hodder \& Stoughton.

Fife-Schaw, C. (2006). Chris's Calculator. Retrieved April 6, 2009, from Department of Psychology, University of Surrey via www.psy.surrey.ac.uk/cfs/docs/ChrisCalcv1_4.xls.

Fromm-Reichmann, F. (1959). Loneliness. Psychiatry, 22, 1-15.

Hartshorne, T. S. (1993). Psychometric properties and confirmatory factor analysis of the UCLA Loneliness Scale. Journal of Personality Assessment, 61, 182-195.

Hawkley, L. C., Burleson, M. H., Berntson, G. G., \& Cacioppo, J. T. (2003). Loneliness in everyday life: Cardiovascular activity, psychosocial context, and health behaviors. Journal of Personality and Social Psychology, 85, 105-120. 
Hecht, D. T., \& Baum, S. K. (1984). Loneliness and attachment patterns in young adults. Journal of Clinical Psychology, 40, 193-197.

Heinrich, L. M., \& Gullone, E. (2006). The clinical significance of loneliness: A literature review. Clinical Psychology Review, 26, 695-718.

Inderbitzen-Pisaruk, H., Clark, M. L., \& Solano C. H. (1992). Correlates of loneliness in midadolescence. Journal of Youth and Adolescence, 21, 151-167.

Johnson, H. D., LaVoie, J. C., Spenceri, M. C., \& Mahoney-Wernli, M. A. (2001). Peer conflict avoidance: Associations with loneliness, social anxiety, and social avoidance. Psychological Reports, 88, 227-235.

Jones, W. H. (1981). Loneliness and social contact. Journal of Social Psychology, 113, 295-296.

Jones, W. H., Carpenter, B. N., \& Quintana, D. (1985). Personality and interpersonal predictors of loneliness in two cultures. Journal of Personality and Social Psychology, 48, 1503-1511.

King, G. A., Specht, J. A., Schultz, I., \& Warr-Leeper, G. (1997). Social skills training for withdrawn unpopular children with physical disabilities: A preliminary evaluation. Rehabilitation Psychology, 42, 47-60.

Koenig, L. J., \& Abrams, R. F. (1999). Adolescent loneliness and adjustment: A focus on gender differences. In K. J. Rotenberg, \& S. Hymel (Eds.), Loneliness in childhood and adolescence (pp. 296-322). New York: Cambridge University Press.

Laine, K. (1998). Finnish students' attributions for school-based loneliness. Scandinavian Journal of Educational Research, 42, 401-413.

Lasgaard, M. (2007). Reliability and validity of the Danish version of the UCLA Loneliness Scale. Personality and Individual Differences, 42, 1359-1366.

Little, R. J. A. (1988). A test of missing completely at random for multivariate data with missing values. Journal of the American Statistical Association, 83, 1198-1202.

Mahon, N. E., Yarcheski, A., Yarcheski, T. J., Cannella, B. L., \& Hanks, M. M. (2006). A metaanalytic study of predictors for loneliness during adolescence. Nursing Research, 55, 308-315. 
Meggert, S. S. (1989). "Who cares what I think?': Problems of low self-esteem. In D. Capuzzi \& D. Gross (Eds), Youth At-Risk: A Resource for Counselors, Teachers and Parents (pp. 97-119). Alexandria, VA: American Association of Counseling and Development.

Moustakas, C. E. (1961). Loneliness. Englewood Cliffs, NJ: Prentice-Hall.

Neto, F., \& Barros, J. (2000). Psychosocial concomitants of loneliness among students of Cape Verde and Portugal. Journal of Psychology, 134, 503-514.

Neto, F., \& Barros, J. (2003). Predictors of loneliness among students and nuns in Angola and Portugal. Journal of Psychology, 137, 351-362.

Nurmi, J., Salmela-Aro, K., \& Haavisto, T. (1995). The Strategy and Attribution Questionnaire: Psychometric properties. European Journal of Psychological Assessment, 11, 108-121.

Nurmi, J., Toivonen, S., Salmela-Aro, K., \& Eronen, S. (1996). Optimistic, approach-oriented, and avoidance strategies in social situations: Three studies on loneliness and peer relationships. European Journal of Personality, 10, 201-219.

Nurmi, J.-E., Toivonen, S., Salmela-Aro, K., \& Eronen, S. (1997). Social strategies and loneliness. Journal of Social Psychology, 137, 764-777.

Peplau, L. A., Miceli, M., \& Morasch, B. (1982). Loneliness and self-evaluation. In L. A. Peplau \& D. Perlman (Eds.), Loneliness: A sourcebook of current theory, research and therapy (pp. 135-151). New York: Wiley.

Peplau, L. A., \& Perlman, D. (1982). Perspectives on loneliness. In L. A. Peplau \& D. Perlman (Eds.), Loneliness: A sourcebook of current theory, research and therapy (pp. 1-18). New York: Wiley.

Reynolds, W. M. (1982). Development of reliable and valid short forms of the Marlowe-Crowne Social Desirability Scale. Journal of Clinical Psychology, 38, 119-125.

Rosenberg, M. (1965). Society and the adolescent self-image. Princeton, N. J: Princeton University Press.

Russell, D. W. (1996). UCLA Loneliness Scale (Version 3): Reliability, validity, and factor structure. Journal of Personality Assessment, 66, 20-40.

Saklofske, D. H., \& Yackulic, R. A. (1989). Personality predictors of loneliness. Personality and Individual Differences, 10, 467-472. 
Saklofske, D. H., Yackulic, R. A., \& Kelly, I. W. (1986). Personality and loneliness. Personality and Individual Differences, 7, 899-901.

Schultz, N. R., \& Moore, D. (1986). The loneliness experience of college students: Sex differences. Personality and Social Psychology Bulletin, 12, 111-119.

Sippola, L. K., \& Bukowski, W. M. (1999). Self and other: Loneliness from a developmental perspective. In K. Rotenberg, \& S. Hymel (Eds.), Loneliness in childhood and adolescence (pp. 280295). New York: Cambridge University Press.

Statistics Denmark (2007a). Students in basic school by age, ancestry, national origin, sex, type of institution and region. Retrieved November 15, 2007, from Statistics Denmark via www.statistikbanken.dk/U19.

Statistics Denmark (2007b). Children by region, age, family type, number of siblings and combination of siblings. Retrieved November 15, 2007, from Statistics Denmark via www.statistikbanken.dk/BRN06.

Stokes, J. P. (1985). The relation of social network and individual difference variables to loneliness. Journal of Personality and Social Psychology, 48, 981-990.

Sullivan, H. (1953). The interpersonal theory of psychiatry. New York: W. W. Norton.

Uruk, A. C., \& Demir, A. (2003). The role of peers and families in predicting the loneliness level of adolescents. Journal of Psychology, 137, 179-193.

Van Buskirk, A. M., \& Duke, M. P. (1991). The relationship between coping style and loneliness in adolescents: Can "sad passivity" be adaptive? Journal of Genetic Psychology, 152, 145-157.

Vaux, A. (1988). Social and emotional loneliness: The role of social and personal characteristics. Personality and Social Psychology Bulletin, 14, 722-734.

Vaux, A. C., Burda, P. C., \& Stewart, D. (1986). Orientation toward utilization of support resources. Journal of Community Psychology, 14, 159-170.

Weiss, R. (1982). Issues in the study of loneliness. In L. Peplau \& D. Perlman (Eds.), Loneliness: A sourcebook of current theory research and therapy (pp. 71-80). New York: Wiley.

Weiss, R. (1973). Loneliness: The experience of emotional and social isolation. Cambridge, MA: MIT Press. 
Wilson, D., Sibanda, J., Sibanda, P., \& Wilson, C. ( 1989). Personality concomitants of loneliness among black and white male Zimbabwean adolescents. Journal of Social Psychology, 129, 577578.

Original received: June $30^{\text {th }}, 2008$

Revision received: January $8^{\text {th }}, 2009$ Accepted: April $23^{\text {th }}, 2009$ 